\title{
IS SECURITY A GREAT PRINCIPLE OF COMPUTING?
}

Invited Talk

Peter J. Denning

Naval Postgraduate School, Monterey, California, USA

In the 1960 s, when computing was still a young discipline, the core courses were automata theory, logic design, numerical analysis, programming, and language translation. These courses represented the core technologies in which a basis of math and science existed. Today there are 20 core technologies and their representatives compete fiercely for slots in the stable of required courses.

Security made its first formal appearance in operating systems around 1960. Today it is a field of its own, competing for slots in core curricula, for tracks and certificates in CS degree programs, and even for status as a Masters Degree program in many schools. Does security deserve this status? Is it a transient response in a time of uncertainty about war? Is it based on deep and enduring principles that merit a place in every computing professional's education?

The approach of aligning the core curriculum with core technologies was good during the early days when the key technologies were few. But today learning the inner workings of 20 technologies and their 400 possible direct interactions is a daunting challenge. A new approach is needed.

A good model comes from the old sciences such as astronomy, life sciences, chemistry, and physics. Each identifies a small set of invariant principles and builds rich structures from the base principles. The newcomer finds this to be a much more rewarding approach because it promotes understanding from the beginning and shows how the science transcends particular technologies. We can adopt this model in computing. 
The principles of computing are in five main categories:

- Computation -- what can be computed and at what cost?

- Communication -- how are data represented and transferred?

- Coordination -- how are computing and work processes coordinated?

- Storage -- how are data named, stored, retrieved, and shared?

- Automation -- what can be automated and at what cost?

But the field cannot be understood by its principles alone. The practices of computing are in four main categories:

- Programming -- using programming languages to write programs that solve problems.

- Systems -- organizing software and hardware components into large, reliable, and dependable systems.

- Modeling -- formulating models of systems in their operating contexts which guide design and configuration.

- Innovation -- designing systems that produce sufficient new value and are adopted into standard practice.

Security is a pervasive concern in all categories of principles and practices.

\section{SPEAKER}

PETER J. DENNING is Professor and Chairman of the Computer Science Department at the Naval Postgraduate School in Monterey, California. He was the founding director of the Research Institute for Advanced Computer Science at the NASA Ames Research Center, was cofounder of CSNET, and was head of the computer science department at Purdue. He received a PhD from MIT and BEE from Manhattan College. He invented the working set model for program behavior and made seminal contributions to performance evaluation. He has published 7 books and 290 articles on computers, networks, and their operating systems, and is working on 3 more books. He was named one of Mason's 5 best teachers in 2002, the best teacher in the School of Information Technology and Engineering, and one of Virginia's 10 Best Teachers. He holds three honorary degrees, three professional society fellowships, two best-paper awards, three distinguished service awards, the ACM Outstanding Contribution Award, the ACM SIGCSE Outstanding CS Educator Award, and the prestigious ACM Karl Karlstrom Outstanding Educator Award. 